\title{
Antimicrobial management of presumed microbial keratitis: guidelines for treatment of central and peripheral ulcers
}

\author{
H G B Bennett, J Hay, C M Kirkness, D V Seal, Penny Devonshire
}

\begin{abstract}
Aims-To determine the quantitative relation between the major risk factors for microbial keratitis of previous ocular surface disease and contact lens wear and central and peripheral infiltration, often associated with ulceration, in order to establish a rational chemotherapeutic management algorithm.
\end{abstract}

Methods-Data from 55 patients were collected over a 10 month period. All cases of presumed microbial keratitis where corneal scrapes had been subjected to microbiological examination were included. Risk factor data and laboratory outcome were recorded. Antimicrobial regimens used to treat each patient were documented.

Results-57 episodes of presumed microbial keratitis were identified from 55 patients, 24 male and 31 female. There were 30 central infiltrates and 27 peripheral infiltrates of which 28 were culture positive $(73 \%$ of central infiltrates, $22 \%$ of peripheral infiltrates). 26 patients had worn contact lenses of whom 12 had culture positive scrapes (9/14 for central infiltrates, 3/12 for peripheral infiltrates). 31 patients had an ocular surface disease of whom five previous herpes simplex virus keratitis patients developed secondary bacterial infection. Anterior chamber activity and an infiltrate size $\geqslant 4 \mathrm{~mm}^{2}$ were more common with culture positive central infiltrates than peripheral infiltrates $\left(\chi^{2}\right.$ test $\left.=11.98, p<0.001\right)$.

Conclusions-Predisposing factors for "presumed" microbial keratitis, either central or peripheral, were: ocular surface disease $(26 / 57=45.6 \%)$, contact lens wear $(26 / 57=45.6 \%)$, and previous trauma $(5 / 57$ $=8.8 \%)$. Larger ulceration $\left(\geqslant 4 \mathrm{~mm}^{2}\right)$ with inflammation was more often associated with positive culture results for central infiltration. None of these four variables (contact lens wear, ocular surface disease, ulcer size, anterior chamber activity) were of intrinsic value in predicting if a peripheral infiltrate would yield identifiable micro-organisms. Successful management of presumed microbial keratitis is aided by a logical approach to therapy, with the use of a defined algorithm of first and second line broad spectrum antimicrobials, for application at each stage of the investigative and treatment process considering central and peripheral infiltration separately.

(Br f Ophthalmol 1998;82:137-145)

Ulcerative keratitis, often microbial in origin, is a sight threatening condition. If diagnosis and initiation of appropriate antimicrobial chemotherapy are delayed, then it has been estimated that only $50 \%$ of eyes will heal with good visual outcome. ${ }^{1}$ It is universally recognised that rapid and unequivocal identification of the causative organism is a prerequisite for provision of rational antimicrobial therapy. ${ }^{2}$ The usefulness of the past ocular history for diagnosis, treatment, and outcome and accurate documentation of the external eye and anterior segment signs cannot be overemphasised..$^{3-4}$

Protocols are available from the USA, Sweden, and the $\mathrm{UK}^{5-7}$ for the management of microbial keratitis, including presumptive disease. Owing to differing disease presentation with climate, environment, and race, however, it was considered appropriate to determine if an algorithmic scheme could be devised for Scotland which would reflect current experience of antimicrobial management. In order to achieve this aim, data were collected on all presentations of presumed and confirmed microbial keratitis over a 10 month period. This allowed recognition of useful clinical markers of culture positive microbial keratitis, and formulation of a modified algorithm $^{2}$ for investigation and chemotherapeutic management of such patients, based on the site of corneal infiltration.

\section{Materials and methods}

\section{PATIENTS AND DATA COLLECTION}

Data were collected from the records of patients who attended either the casualty or outpatient department of the Glasgow Eye Infirmary or who became inpatients in the Western Infirmary or Gartnavel General Hospitals, Glasgow. All patients whose management involved the collection of corneal scrapings were included, except those with active herpetic or adenoviral infection, without secondary microbial infection, who were excluded. The study was performed over a 10 month period.

Patients were obtained from the microbiology department computer database. A novel database was constructed to record patient details. These included: (a) characteristics of ulcer/infiltrate (site, size, anterior chamber activity); (b) experience of ocular trauma,
Accepted for publication 27 August 1997 
previous or current ocular surface disease (sicca, blepharitis, including meibomianitis, previous herpes simplex virus (HSV) keratitis, rosacea, and others); (c) results of microbiological investigations; (d) treatments used and their effects; and (e) contact lens use, and where appropriate, details of hygiene practice. If data were incomplete, individuals were followed up by telephone inquiries. Details of contact lens types used (classified in this study as Food and Drug Administration (FDA) groups 1 and 2 (non-ionic, low, and high water content) and FDA groups 3 and 4 (ionic, low, and high water content)), as well as use of solutions and cleaning agents were recorded. It was determined if contact lens wearers had used tap water as part of their lens cleaning/ disinfection practice, an important factor in the aetiology of Acanthamoeba keratitis.

A

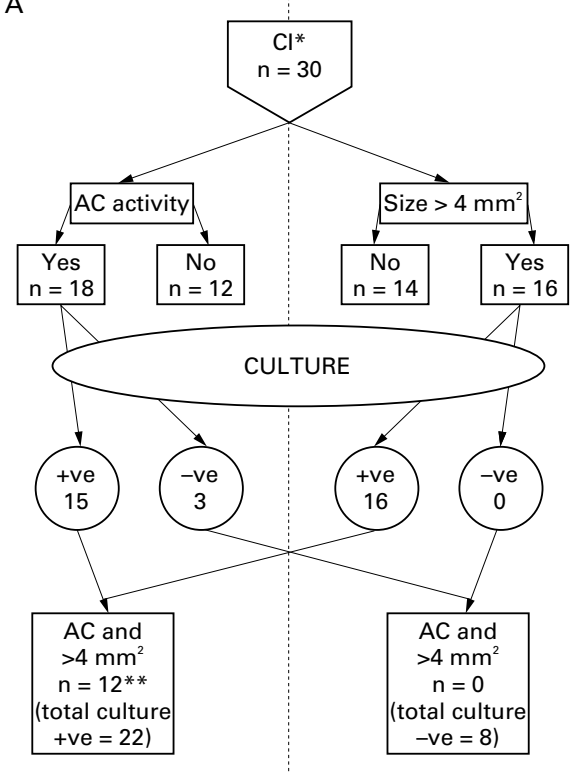

B

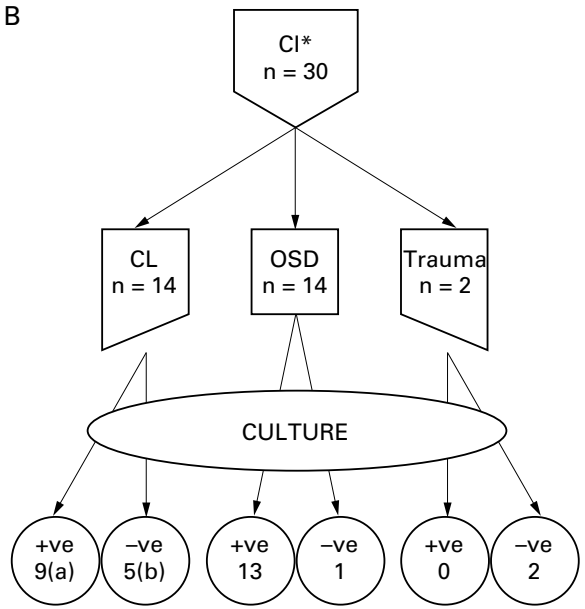

Patients included in this study were assigned to one of two categories, based on the site of the major part of the infiltrate. These were: (a) central infiltrates, which presented in a central $6 \mathrm{~mm}$ diameter zone of cornea; and (b) peripheral infiltrates, which manifested within $2 \mathrm{~mm}$ of the limbus.

LABORATORY INVESTIGATION

Routine bacteriology (microscopy with Gram's stain and culture) was performed on all corneal scrape specimens from patients with presumptive keratitis. ${ }^{9}$ Culture involved chocolate and blood agars, with incubation in 5\% carbon dioxide for 48 hours. Anaerobic culture media were not inoculated routinely. Bacteria were classified using standard techniques (API system). Antibiotic sensitivity tests were performed routinely. If there was a high index of
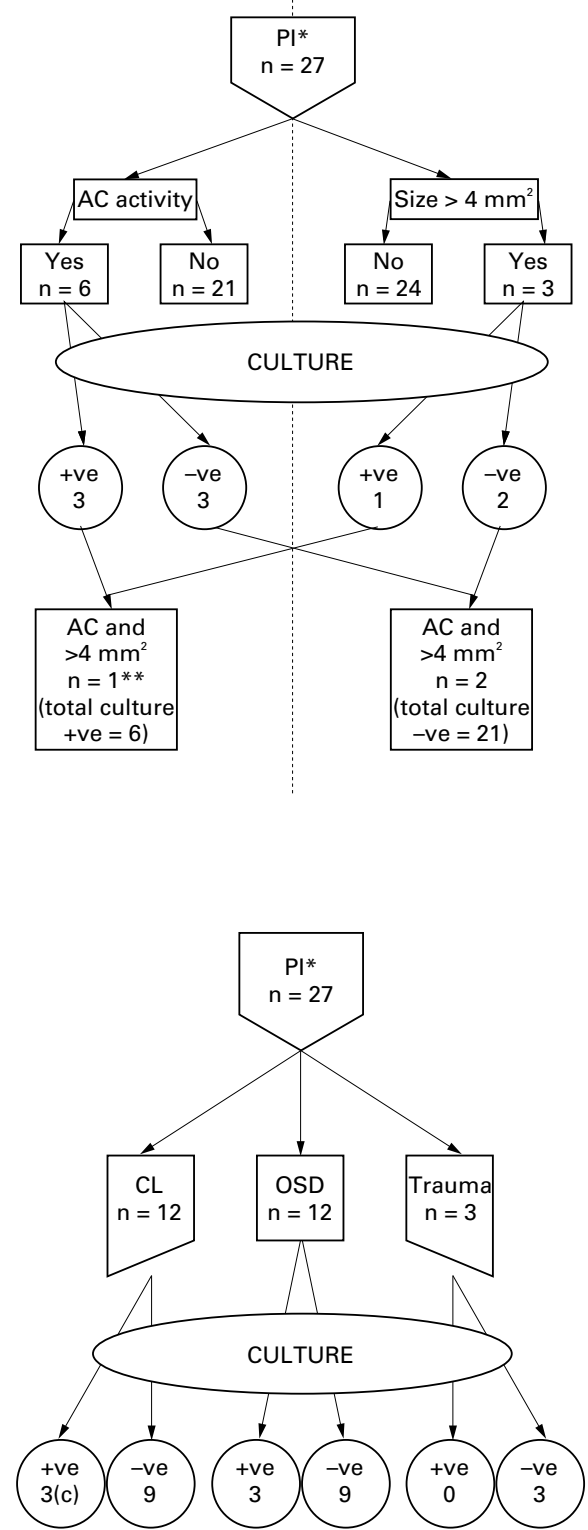

Figure 1 (A) Clinical signs: predictors of a positive culture result. (B) Predisposing risk factors for microbial keratitis. ${ }^{\star} C I$ $=$ central infiltration; $P I=$ peripheral infiltration. $O C D=$ ocular surface disease. ${ }^{\star \star}$ Excludes all patients with Acanthamoeba and Vahlkampfia keratitis (since no infiltrate $\geqslant 4 \mathrm{~mm}^{2}$ ). (a) Three extended wear contact lenses (one congenital cataract, 0.05 years; one chronic allergic keratoconjunctivitis; one band-shaped keratopathy: former two, $S$ pneumoniae, latter, $S$ aureus). (b) Two presentations due to contact lens associated keratopathy (CLAK). (c) One extended wear contact lens (exposure keratopathy due to $S$ aureus). 
Table 1 Micro-organisms isolated from CI and PI. Contact lens (CL) wear is indicated. All cases demonstrating anterior chamber $(A C)$ activity in combination with an infiltrate size $\geqslant 4 \mathrm{~mm}^{2}$ are shown

\begin{tabular}{|c|c|c|c|c|c|c|}
\hline \multirow[b]{2}{*}{ Micro-organism * } & \multicolumn{3}{|c|}{ Central infiltrate $(C I)$} & \multicolumn{3}{|c|}{ Peripheral infiltrate (PI) } \\
\hline & Total & $C L$ wearers & $\begin{array}{l}\text { AC activity } \\
+\geqslant 4 \mathrm{~mm}^{2}\end{array}$ & Total & $C L$ wearers & $\begin{array}{l}\text { AC activity } \\
+\geqslant 4 \mathrm{~mm}^{2}\end{array}$ \\
\hline Acanthamoeba & 4 & 4 & $t$ & 0 & 0 & 0 \\
\hline Vahlkampfia & 0 & 0 & 0 & 1 & 1 & $\dagger$ \\
\hline$S$ aureus & 4 & 1 & 3 & 2 & 1 & 0 \\
\hline CNS & 4 & 1 & 2 & 0 & 0 & 0 \\
\hline$S$ pneumoniae & 3 & 2 & 1 & 2 & 0 & 1 \\
\hline$S$ viridans & 1 & 0 & 1 & 0 & 0 & 0 \\
\hline$\alpha$ Haem strep & 1 & 0 & 1 & 0 & 0 & 0 \\
\hline Ps aeruginosa & 2 & 1 & 2 & 1 & 1 & 0 \\
\hline Acinetobacter $\mathrm{sp}$ & 1 & 0 & 1 & 0 & 0 & 0 \\
\hline Nocardia sp & 1 & 0 & 1 & 0 & 0 & 0 \\
\hline Sporotrichon $\mathrm{sp}$ & 1 & 0 & 0 & 0 & 0 & 0 \\
\hline Totals & 22 & 9 & 12 & 6 & 3 & 1 \\
\hline
\end{tabular}

CNS = coagulase negative staphylococci; $\alpha$ Haem strep $=\alpha$ haemolytic streptococci.

*See Figure 2 for examples of clinical presentations of different infections.

†Excludes all patients with Acanthamoeba or Vahlkampfia keratitis (no infiltrate $\geqslant 4 \mathrm{~mm}^{2}$ ).

clinical suspicion of an atypical organism causing keratitis (progressive disease with failure to respond to first line broad spectrum antibacterial therapy or typical clinical signs such as keratoneuritis of Acanthamoeba infection-see Fig 2(g)), additional microbiological tests were performed. For the present study this involved a modified Ziehl-Neelsen stain, decolorising with $5 \%$ acetic acid without alcohol, for acid and non-alcohol fast bacilli. For attempted isolation of Nocardia species, prolonged culture at $37^{\circ} \mathrm{C}$ in $5 \%$ carbon dioxide for 1 week was performed on chocolate agar. For Mycobacterium species, Lowenstein-Jensen medium was used. For fungal identification, light microscopy was used on Gram and periodic acid Schiff (PAS) stained smears. Fungal culture was performed using Sabouraud's agar, plates being incubated at $30^{\circ} \mathrm{C}$ for 2 weeks. For patients with suspected infection due to Acanthamoeba, or with other free living amoebae known to cause keratitis, microscopy and culture of corneal tissue were used. ${ }^{10-12}$ Briefly, aliquots of the corneal scrape samples were examined in a wet preparation directly using phase or bright field microscopy; this was followed by culture on non-nutrient agar seeded with heat killed $\mathrm{Kleb}$ siella bacteria. Plates were incubated at $25^{\circ} \mathrm{C}$ or $32^{\circ} \mathrm{C}$ for 4 weeks, and examined intermittently for growth of the protozoa. Sensitivity testing for Acanthamoeba was performed as previously described. ${ }^{13}$

\section{Results}

PATIENTS AND OCULAR FEATURES

Figure 1 illustrates the findings for the clinical signs presented by the patients with presumed microbial keratitis, 30 with central infiltration and 27 with peripheral infiltration; 26 patients wore contact lenses, 26 had ocular surface disease, and five had suffered previous trauma. Twenty four patients (42\%) presented with anterior chamber activity-18 patients had central infiltration and only three failed to provide positive culture results; the remaining six patients had peripheral infiltration, three being culture positive and three culture negative. The surface area of the cornea for each infiltrated ulcer was calculated from recorded measurements. A surface area greater than or equal to 4 $\mathrm{mm}^{2}$ was involved in 19 patients and was associated with a greater frequency of positive culture results-16 were central infiltrates, all being culture positive, and three were peripheral infiltrates with one being culture positive $\left(\chi^{2}\right.$ test $\left.=18.56, \mathrm{p}<0.001\right)$. For contact lens wearers, there were 14 central infiltrates and nine were culture positive compared with three out of 12 for the peripheral infiltrates, but this was not significant $\left(\chi^{2}\right.$ test $\left.=3.77, \mathrm{p}<0.1\right)$. For ocular surface disease, there were 14 central infiltrates and 13 were culture positive compared with three out of 12 for the peripheral infiltrates, and this was significant $\left(\chi^{2}\right.$ test $=$ 12.57, $\mathrm{p}<0.001)$. All five patients who were

Table 2 Patients successfully treated at each stage of management including use of immunomodulatory drugs $(n)^{1-T V}$

\begin{tabular}{|c|c|c|c|c|c|c|c|}
\hline \multirow[b]{2}{*}{ Infiltration } & & \multicolumn{3}{|c|}{ Successfully treated with: } & \multirow[b]{2}{*}{$\begin{array}{l}\text { Failed 3rd } \\
\text { line } R x\end{array}$} & \multirow[b]{2}{*}{$\begin{array}{l}\text { No antibiotic } \\
\text { treatment }\end{array}$} & \multirow[b]{2}{*}{ Totals } \\
\hline & & $\begin{array}{l}\text { 1st line BS Rx for } \\
\text { putative pathogens }\end{array}$ & $\begin{array}{l}\text { Specific Rx after pathogen } \\
\text { culture and sensitivities }\end{array}$ & $\begin{array}{l}\text { 2nd line } B S \\
R x\end{array}$ & & & \\
\hline \multirow[t]{2}{*}{ Central } & culture +ve & $14^{\mathrm{a}}(2)^{\mathrm{I}}(1)^{\mathrm{II}}$ & $5^{\mathrm{b}}$ & $1^{c}$ & $2^{\mathrm{d}}(1)^{\mathrm{I}}$ & 0 & 22 \\
\hline & culture -ve & 6 & NA & 0 & 0 & 2 & 8 \\
\hline \multirow{2}{*}{ Peripheral } & culture + ve & 5 & $1^{\mathrm{e}}$ & 0 & 0 & 0 & 6 \\
\hline & culture -ve & $15(1)^{\mathrm{I}+\mathrm{II}}(1)^{\mathrm{III}}$ & NA & $(4)^{\mathrm{I}}(1)^{\mathrm{III}}(1)^{\mathrm{IV}}$ & 0 & 0 & 21 \\
\hline Totals & & 40 & 6 & 7 & 2 & 2 & 57 \\
\hline
\end{tabular}

BS = broad spectrum.

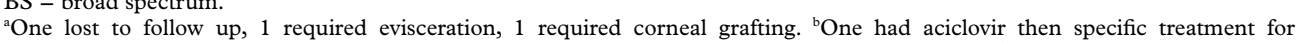
Acanthamoeba, 2 patients had Ps aeruginosa, 1 had $S$ pneumoniae, and another $S$ aureus. ${ }^{\circ}$ Nocardia sp. ${ }^{\mathrm{d} S e v e r e}$ ocular surface disease, not responsive to antibiotics provided. ${ }^{\mathrm{e}}$ Addition of penicillin for $S$ pneumoniae.

${ }^{\mathrm{I}}$ Prednisolone topically. ${ }^{\mathrm{II}}$ Methylprednisolone intravenously. ${ }^{\mathrm{II}} \mathrm{Fucidin}$ topically. ${ }^{\mathrm{IV}} \mathrm{Tetracycline}$ orally. 


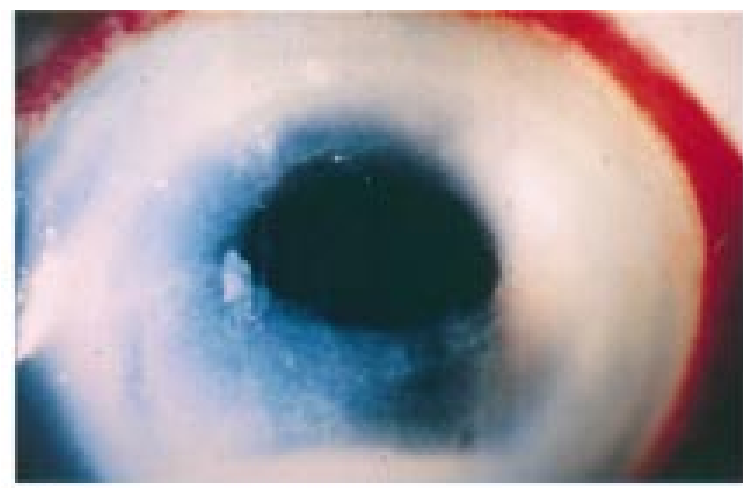

a

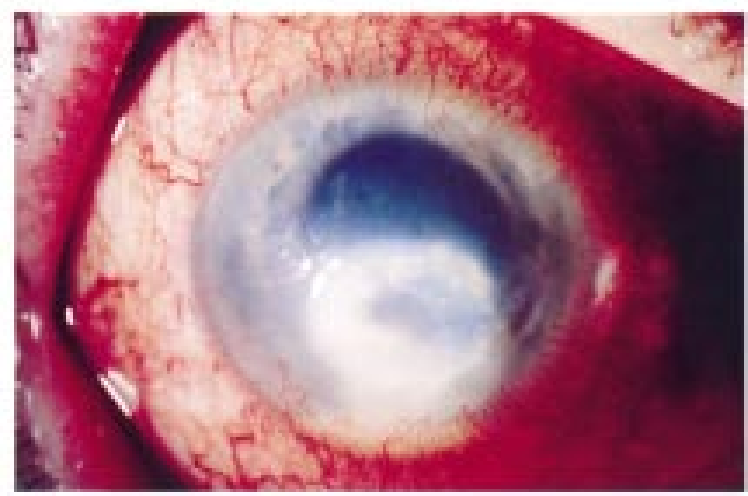

C

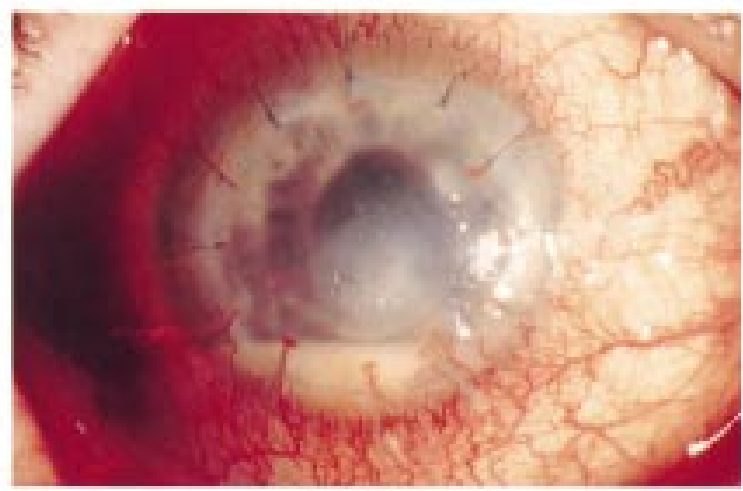

e

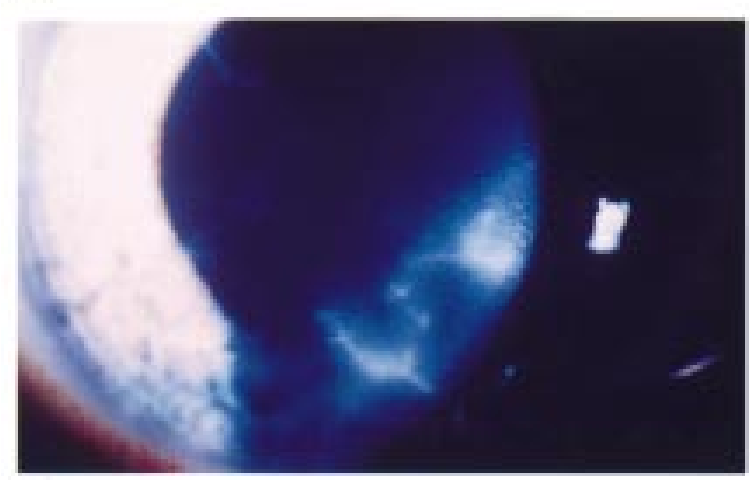

g

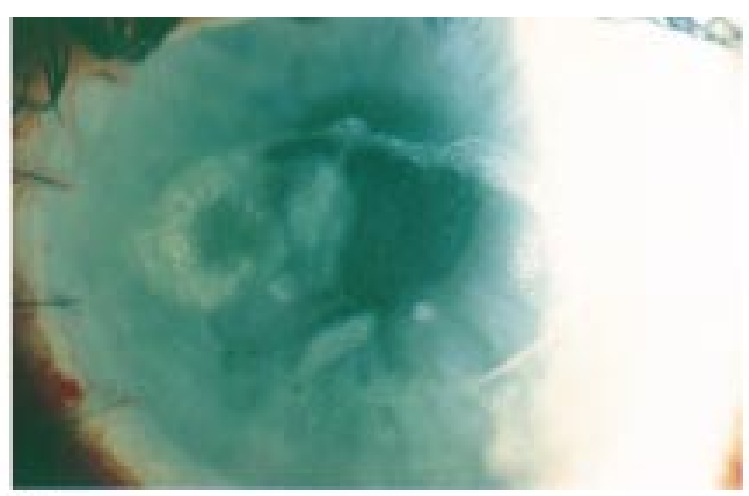

b

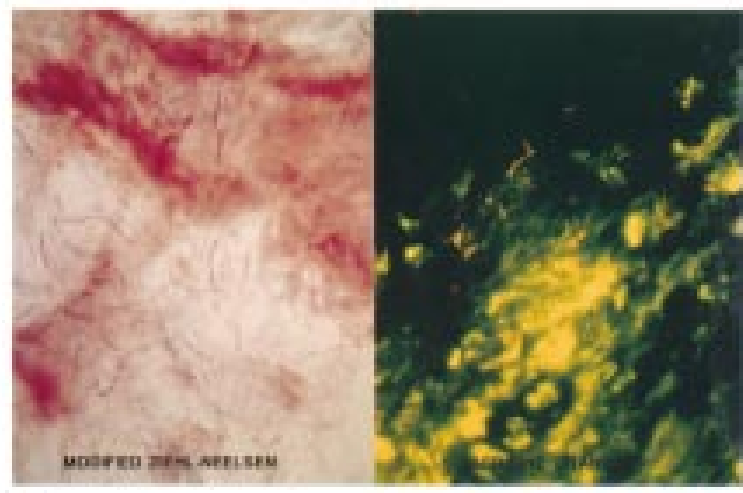

d
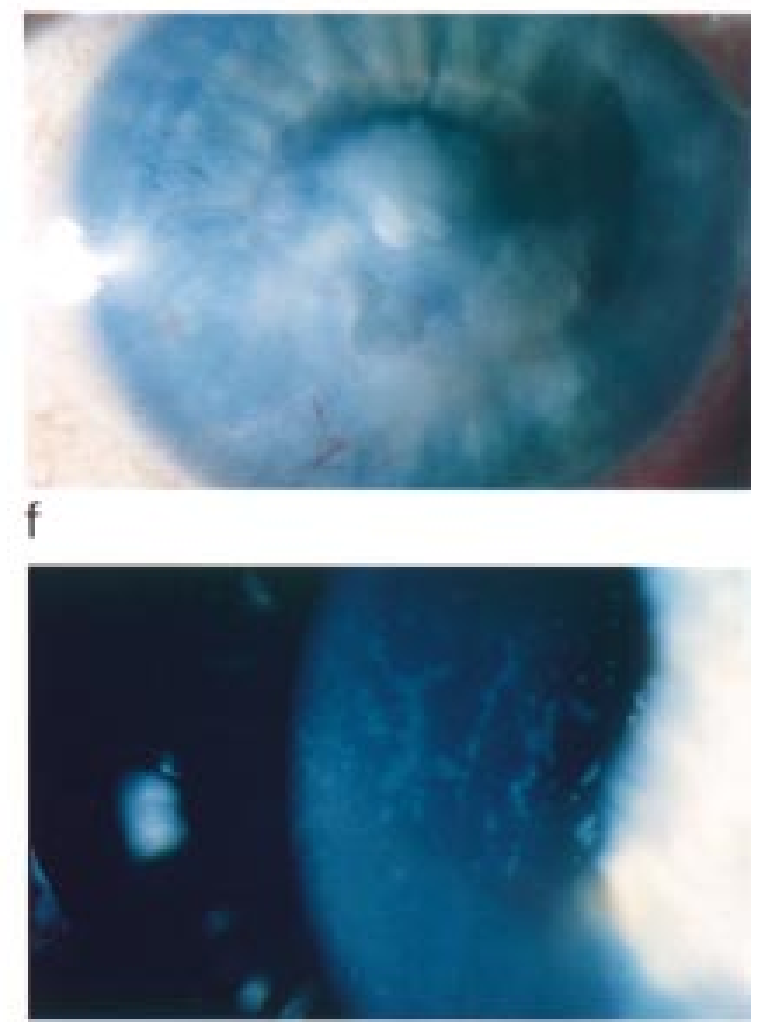

h

Figure 2 (a) Pseudomonas aeruginosa keratitis with central desmetocele. Infection from use of contaminated cosmetic eyedrops. (b) Sporotrichon keratitis in patient A, 4 months after penetrating keratoplasty. (c) Nocardia keratitis in patient with mild ocular cicatricial pemphigoid. (d) Modified Ziehl-Neelsen (left) and acridine orange (right) stains of corneal biopsy material from patient $C$ showing presence of Nocardia species. (e) Staphylococcus aureus keratitis in patient $C, 5$ months after lamellar keratoplasty. (f) Acinetobacter haemolyticus keratitis in a patient with a history of severe herpes simplex keratitis and secondary corneal vascularisation. (g) Acanthamoeba keratitis in a soft contact lens wearer (FDA group 4) who used chlorine based disinfection and tap water for contact lens hygiene. (h) Contact lens associated keratitis (CLAK) in a soft contact lens wearer (FDA group 1) who used both hydrogen peroxide based disinfection and tap water for contact lens hygiene. 
Table 3 First and second line broad spectrum therapy

\section{First line:}

Suspected pathogen: Bacteria

Fungi

Amoebae

Second line:

Suspected pathogen:

Fastidious bacteria

Fungi

Amoebae

$S$ pneumoniae, use penicillin $0.3 \%$ instead.

${ }^{\mathrm{b}}$ Ps aeruginos $a$, add ticarcillin $5 \%$ or ceftazidime $5 \%$ or ciprofloxacin $0.3 \%$.

c Ciprofloxacin $0.3 \%$ and ofloxacin $0.3 \%$ are commercially available in UK.

${ }^{\mathrm{d}}$ Natamycin is not commercially available in UK

Withhold steroids unless already in use before presentation.

known to have had previous HSV keratitis were culture positive (four central infiltrates, one peripheral infiltrate).

Table 1 shows the variety of microorganisms which were detected within the central infiltration and peripheral infiltration groups. Overall, a total of $17 / 28(61 \%)$ culture positive presentations were due to Gram positive bacteria, $4 / 28(14 \%)$ were due to Gram negative bacteria, $5 / 28(18 \%)$ were caused by amoebae, and $2 / 28(7 \%)$ were due to yeasts. Ten of $28(36 \%)$ were caused by staphylococcal species-six Staphylococcus aureus and four coagulase negative staphylococci (CNS). The majority of these (7/10) were found in non-contact lens wearers.

All cases of amoeba associated microbial keratitis (four Acanthamoeba with one putative Vahlkampfia) and two out of three cases of Pseudomonas aeruginosa were found in contact lens wearers. The five patients with a definite history of corneal trauma were all culture negative.

The non-contact lens wearing patient infected with $P$ s aeruginosa may have traumatised the cornea with a mascara brush but she had been using opened, and subsequently contaminated, cosmetic eyedrops (Eyedew (adrenaline), Boots plc) while sunbathing on holiday in Spain. On return from vacation the patient presented with severe microbial keratitis involving the whole cornea with a central desmetocele (Fig 2(a)). Ps aeruginosa was isolated from the cornea and the eyedrops. This patient required both antipseudomonal chemotherapy (gentamicin, ticarcillin, and ciprofloxacin) and a penetrating keratoplasty. Corticosteroids were also given but antibiotics were continued for over 1 month to eradicate all remaining bacteria to avoid recurrence. The graft became infected 4 months later with Sporotrichon species (Fig 2(b)) while the patient was on vacation in Florida.

The treatment responses of all patients included in this study are summarised in Table 2 including use of corticosteroids and immunomodulatory drugs. It can be seen that $53 / 57$ presumptive microbial keratitis episodes responded to appropriate treatment, whether broad spectrum or specifically targeted at cultured organisms. Two patients failed third line therapy and both had severe ocular surface disease. The remaining two patients, both contact lens wearers, required no therapy; these individuals had contact lens associated keratitis (CLAK), a novel presentation (considered below).

\section{Discussion}

In this study, $73 \%(22 / 30)$ of corneal scrapes from patients with presumed microbial keratitis and central infiltration were culture positive, of whom $47 \%$ (14/30) wore contact lens. This is comparable with a 3 year prospective study of presumed microbial keratitis of the central cornea in Gothenburg, when $63 \%(36 / 48)$ of patients had positive cultures and 10/18 contact lens wearers had proved corneal infection. ${ }^{6}$ In the present study, 59\% (13/22) of identified organisms were Gram positive bacteria, compared with $70 \%$ recorded from Gothenburg, while 14\% (3/22) were Gram negative bacteria and $18 \%(4 / 22)$ were due to Acanthamoeba: these protozoa were not isolated in the Gothenburg study.

The presence of four cases of Acanthamoeba in contact lens wearers may be attributable to varying contact lens hygiene practice between the two countries. Chlorine based disinfection is especially problematic for the contact lens wearer, and is a suspected risk factor for Acanthamoeba keratitis. ${ }^{14-19}$ This risk is enhanced if tap water, a recognised source for transfer of Acanthamoeba into the storage case, is used as part of the contact lens hygiene regimen. ${ }^{8}$ Three of the four patients in this study, with culture proved Acanthamoeba keratitis, admitted to use of tap water in their contact lens hygiene regimen and all four had Acanthamoeba isolated from their storage case. Two used no contact lens disinfectant, one had been recommended the weak chlorine generating system at 3-4 ppm active chlorine (Softab, Alcon) and the other used a hydrogen peroxide based product but misused it by mixing it with tap water.

A changing pattern in micro-organisms cultured from corneal scrapes has been demonstrated in a survey of 30 years' laboratory experience of investigating 677 cases of presumed microbial keratitis in New York. ${ }^{5}$ During the first 10 years of the study (1950-9), $55 \%$ of bacterial isolates were Gram positive, with the remainder (45\%) being Gram negative. This was modified during 1970-9 where the figures were $83 \%$ and $17 \%$ respectively. Pseudomonas species, seen in burns and intensive care patients, declined in frequency to a greater extent than other infections over the 30 year investigation. Moraxella species, isolated from malnourished individuals, was not isolated during our present study.

The relation between the observed microbial spectrum and climatic conditions is important. In temperate climates Gram positive bacteria and Acanthamoeba, associated with contact lens wear, are the most common isolates. This compares with Ps aeruginosa and filamentous mycelial fungi which predominate in tropical and semitropical areas. ${ }^{20-26}$ In the latter situation, Acanthamoeba is usually a non-contact lens associated infection ${ }^{27}$ or can be detected as chronic microbial keratitis. ${ }^{28}$ Within a hot country such as India, there can be variation in 
microbial keratitis isolates with greater detection of Aspergillus species in northern India, ${ }^{29}$ with very hot dry summers, compared with filamentous fungi such as Lasiodiplodia theobromae in southern India where there is a tropical climate. ${ }^{30}$ The same situation applies between northern and southern states in the USA. ${ }^{31}{ }^{32}$

Currently, Gram negative bacteria are less frequently involved in cases of microbial keratitis in temperate climates. There may, however, be a local or systemic predisposing disorder in the patient such as leukaemia or lymphoma and this should always be considered. Ps aeruginosa has been identified, as well as Serratia and Proteus species, in microbial keratitis after application of contaminated ocular medications to the eye. ${ }^{33}$ One such presentation caused by $P$ s aeruginosa has been described in the present study (see Results).

All 57 patients in this study were initially managed empirically with first line broad spectrum antimicrobial treatment of topical gentamicin and cefuroxime. Table 2 shows that $14 / 22(64 \%)$ patients with central infiltration and culture positive microbial keratitis were successfully treated: a further five responded when treatment was modified after culture findings became available; three required a second line broad spectrum approach, of whom two failed to respond as their keratitis was primarily due to severe ocular surface disease (atopy with recurrent HSV keratitis ${ }^{34}$ and ocular cicatricial pemphigoid). In one patient with mild ocular cicatricial pemphigoid, the underlying cause of the microbial keratitis was not recognised for 6 months (Fig 2(c)), until a modified Ziehl-Neelsen stain (Fig 2(d)) revealed the presence of Nocardia infection. ${ }^{35}$ The patient responded well to lamellar corneal grafting, in combination with the appropriate antimicrobial therapy of topical amikacin, vancomycin, and trimethoprim (as Polytrim). The patient represented during the study period with a second episode of microbial keratitis, on this occasion due to $S$ aureus (Fig 2(e)). This infection was treated successfully with frequent drop therapy of cefuroxime $5 \%$ and gentamicin $1.5 \%$. Recommended broad spectrum and specific antimicrobial chemotherapy based on the experience of the present study are given in Table $3(1 \% \equiv 10 \mathrm{mg} / \mathrm{ml})$.

Topical therapy should be given every 5 minutes for the first 15 minutes, every 15 minutes for the first hour, and then hourly by day and night for the first 3 days before reducing to 2 hourly by day according to the patient's progress and the discretion of the attending doctor. If topical cefuroxime $5 \%$ cannot be produced by the hospital pharmacy, then topical ciprofloxacin $0.3 \%$ or ofloxacin $0.3 \%$ can be used as single drug therapy, available commercially, as they have both been shown as effective as the combination of an aminoglycoside and a cephalosporin. ${ }^{36} 37$ The argument against relying on use of the quinolone drugs is the potential development of resistance already experienced with systemic use in hospitals.

Fourteen of $26(56 \%)$ contact lens wearers with presumed microbial keratitis were culture negative but all responded rapidly when treated with topical antibiotics and removal of the contact lens. Some of these patients, in particular with peripheral infiltration, probably had sterile corneal infiltrates. This phenomenon, in particular when associated with soft contact lens wear, and concurrent poor contact lens hygiene, has been reported previously. ${ }^{38} 39$ These infiltrates are varyingly thought to be due to immunological or toxic reactions to contact lens material, the cleaning/disinfecting solutions used, ${ }^{40}$ or to Gram negative bacteria being adherent to the contact lens. ${ }^{41}$ Such presentations may represent early or abortive infections. Distinguishing between infected and sterile infiltrates in contact lens wearers, particularly in the case of peripheral infiltrates, is an important step in management, and may be guided by clinical symptoms and signs. Central and painful infiltrates associated with epithelial staining, with ulceration (Fig 2(f)) or anterior chamber reaction (keratic precipitates or hypopyon), were suggested to denote infection in one prospective study. ${ }^{38}$ It must never be assumed that it is safe not to scrape contact lens associated peripheral infiltration since the results from the present study show that scrapes from 3/12 of such patients were culture positive, with two having virulent bacteria $(S$ aureus, Ps aeruginosa) present.

Two teenage patients (using either an FDA group 1 or 4 soft contact lens for daily wear) had a central infiltration, initially thought to be due to Acanthamoeba. The contact lens wearers were non-compliant with their hygiene regimens and admitted to rinsing their contact lens in domestic tap water. There was lid swelling and conjunctival hyperaemia with punctate and irregularly shaped linear infiltrates in the central corneal epithelium (Fig 2(h)), suggestive, but not entirely typical, of early Acanthamoeba keratitis. Keratoneuritis, typical of early Acanthamoeba keratitis (Fig 2(g)), was not detected and limbitis was absent. Pain was not severe. The patients were managed by withdrawing the contact lens while further investigations ensued. After 1 week their corneal signs and symptoms had abated without the need for chemotherapy. These presentations, considered to represent collectively a phenomenon duly named contact lens associated keratitis (CLAK), may be equivalent to previously recorded "tight fit" or so called "over-wear contact lens syndrome". ${ }^{42}$ Preserved or potentially toxic disinfecting/ cleaning solutions may also have contributed to these presentations. It has been shown that when such solutions were discontinued, and thermal disinfection instituted, the condition disappeared. ${ }^{40}{ }^{43}$ Other factors such as contact lens polymer type and modality of contact lens worn may contribute to this condition. ${ }^{44-46}$ The differential diagnosis of this new syndrome (CLAK) from both adenovirus and Acanthamoeba infection ${ }^{47}$ is important, since contact lens wearing patients may be unnecessarily treated for "culture negative" Acanthamoeba keratitis.

It can be seen from Table 2 that a total of 12 patients were treated at different stages of their management with disease modifying drugs. 


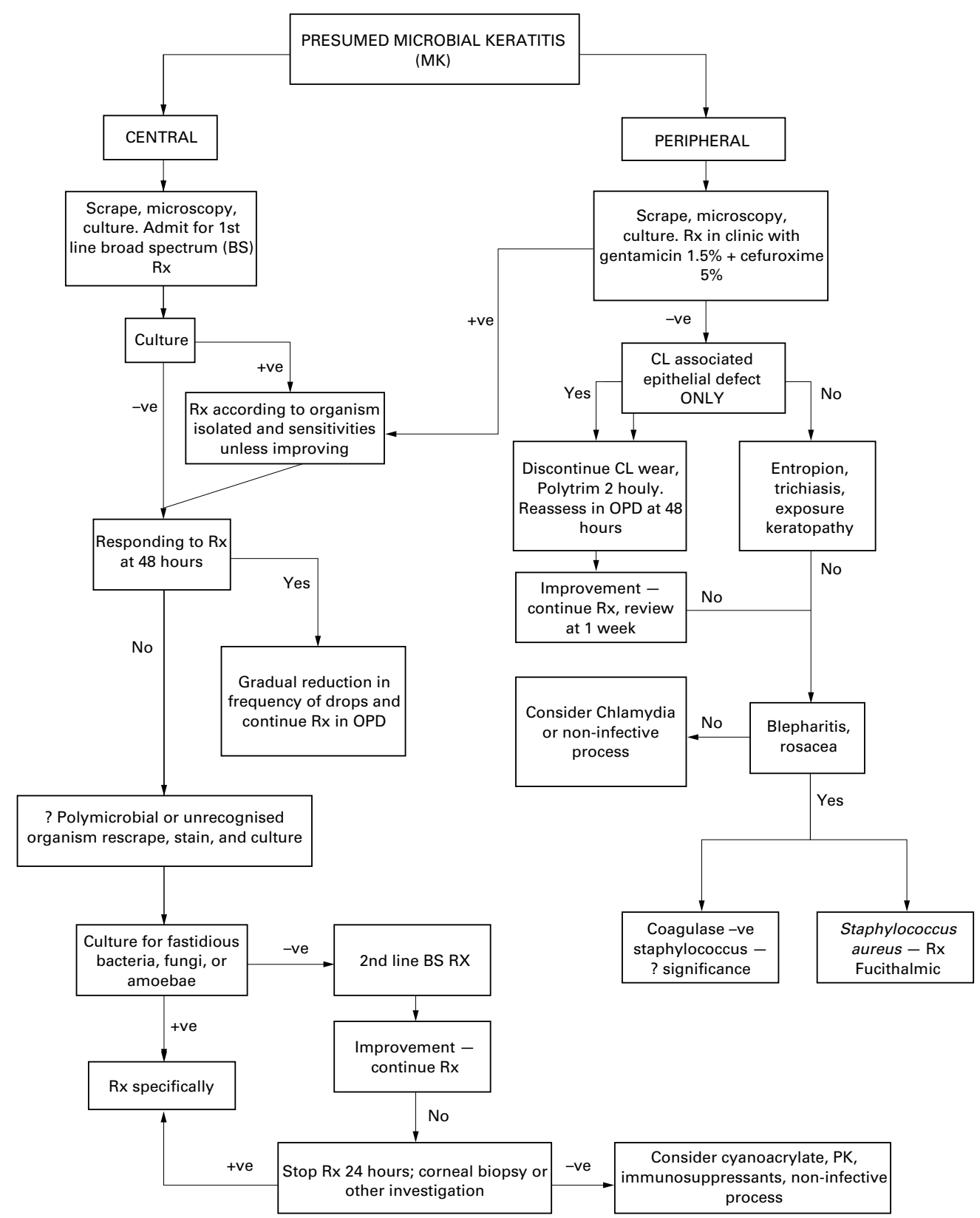

Figure 3 Chemotherapeutic algorithm for the management of presumed microbial keratitis.

The four patients with central infiltration were all culture positive with three demonstrating ocular surface disease, including two cases of previous HSV keratitis who were given additionally antiviral treatment before the growth of a definitive organism. The other case required an urgent penetrating keratoplasty for severe Ps aeruginosa keratitis and intravenous methylprednisolone therapy was indicated because of associated scleritis. In contrast, all of the eight patients with peripheral infiltration were culture negative. Six cases demonstrated blepharitis and responded well to treatment for marginal keratitis. Another patient showed features of rosacea and hence treatment with oxytetracycline was commenced. The final patient in this group had recently had a trabeculectomy, subsequently developing a hypopyon ulcer with raised intraocular pres- sure. Intravenous methylprednisolone was added to a postoperative regimen which already included a steroid in the form of topical prednisolone acetate.

The use of corticosteroid therapy to treat infectious corneal disease has continued to be an apparently necessary, but none the less controversial, treatment. ${ }^{48-50}$

It has been suggested that outpatient treatment can be instituted for the management of patients with microbial corneal ulcers. ${ }^{51}$ The reliability of patient compliance with therapy provided and their understanding of the degree of severity of the keratitis must be evaluated in each case. In the catchment area of the present study it is considered from experience that patients cannot be relied upon to instil eyedrops frequently; hence inpatient treatment is the usual means of delivering care for 
individuals requiring continuous antimicrobial chemotherapy for microbial keratitis.

We have modified a previous algorithm ${ }^{2}$ to produce a simple stepwise approach for investigation and treatment of presumed microbial keratitis as experienced in Scotland. The new algorithm (Fig 3) categorises each patient as having a central or peripheral infiltrate at the time of presentation. Suggested broad spectrum antibiotic treatment includes combinations for first and second line antimicrobial chemotherapy. Further specific treatments for fastidious bacteria, such as Nocardia and Mycobacteria species, are included together with our treatment of Acanthamoeba keratitis, ${ }^{12}$ which comprises the combination of chlorhexidine $(0.02 \%$ $\mathrm{w} / \mathrm{v})$ and propamidine ( $0.1 \%$, as Brolene).

Special consideration will be required for groups of patients who are not specifically referred to in this study. These include children with microbial keratitis ${ }^{52}{ }^{53}$; those with anaerobic corneal ulcers ${ }^{54}$; and those who are severely immunocompromised, as with HIV or AIDS. ${ }^{556}$ The proposed algorithm includes microscopy and culture of corneal biopsy samples. ${ }^{57}$ The main indications for biopsy are: (1) progressive severe keratitis with negative cultures (as in one of our patients); (2) non-healing keratitis of unknown aetiology; (3) chronic refractory keratitis; or (4) keratitis with a possibly infected infiltrate-for example, "crystalline keratopathy", that cannot be scraped adequately.

This study has provided useful information regarding various factors which influence the management of presumed microbial keratitis. Firstly, central infiltrations were more frequently culture positive $(73 \%)$ than were peripheral infiltrations $(22 \%)\left(\chi^{2}\right.$ test $=14.85$, $\mathrm{p}<0.001)$. Secondly, anterior chamber activity was documented in $64 \%$ of culture positive patients, but in only $21 \%$ of culture negative ones $\left(\chi^{2}\right.$ test $\left.=11.1, \mathrm{p}<0.001\right)$. Thirdly, $61 \%$ of culture positive patients showed corneal infiltration of surface area $\geqslant 4 \mathrm{~mm}^{2}$ while less than $7 \%$ of culture negative cases were of this dimension $\left(\chi^{2}\right.$ test $\left.=18.56, \quad \mathrm{p}<0.001\right)$. Fourthly, anterior chamber activity and an infiltrate size $\geqslant 4 \mathrm{~mm}^{2}$ were more common with culture positive central infiltration than peripheral infiltration $\left(\chi^{2}\right.$ test $=11.98$, $\mathrm{p}<0.001)$. Risk factors for presumed microbial keratitis included ocular surface disease $(46 \%)$, contact lens wear $(46 \%)$, and trauma $(8 \%)$, although the latter were culture negative in this series. There was no case of presumed or proved microbial keratitis in an otherwise normal, non-contact lens wearing eye.

\section{Addendum}

Instead of Polytrim for the second line broad spectrum therapy, intravenous Bactrim can be used as a "forte" preparation which contains no preservatives; place the neat intravenous preparation into an eye dropper bottle and apply with frequent doses.

This study was partly supported by the Wallace Brown Memorial Trust.

We acknowledge the help of Mr John McCormick, ophthalmic photographer, Tennent Institute of Ophthalmology.
1 Jones DB. Decision-making in the management of microbial keratitis. Ophthalmology 1981;88:814-20.

2 Ficker L, Kirkness CM, McCartney ACE, Seal DV. Microbial keratitis - the false negative. Eye 1991;5:549-59.

3 Pavesio CE, Dart JKG. Microbial eye disease. Current Medical Literature (Ophthalmology) 1992;2:63-7.

4 McLeod SD, DeBacker CM, Viana MAG. Differential care of corneal ulcers in the community based on apparent severity. Ophthalmology 1995;103:479-84.

5 Asbell P, Stenson S. Ulcerative keratitis - survey of 30 years' laboratory experience. Arch Ophthalmol 1982;100:77-80.

6 Neumann M, Sjöstrand J. Central microbial keratitis in a Swedish city population-a three-year prospective study in Swedish city population-a three-year prospective

7 Allan BDS, Dart JKG. Strategies for the management of microbial keratitis. Br f Ophthalmol 1995;79:777-86.

8 Ledee DR, Hay J, Byers TJ, Seal DV, Kirkness CM Acanthamoeba griffini: molecular characterisation of a new corneal pathogen. Invest Ophthalmol Vis Sci 1996;37:54450.

9 Benson WH, Lanier D. Comparison of techniques for culturing corneal ulcers. Ophthalmology 1992;99:800-4.

10 Aitken D, Hay J, Kinnear F, et al. Amoebic keratitis in a wearer of disposable contact lenses due to a mixed Vahlkampfia and Hartmannella infection. Ophthalmology 1996;103:485-94.

11 Kennedy H, Devine P, Hurley C, Ooi Y-S, Collum LMT. Corneal infection associated with Hartmannella vermi-
formis in a contact lens wearer. Lancet 1995;346:637-8.

12 Seal DV, Hay J, Kirkness CM, et al. Successful medical therapy of Acanthamoeba keratitis with topical chlorhexidine and propamidine. Eye 1996;10:413-21.

13 Hay J, Kirkness CM, Seal DV, Wright P. Drug resistance and Acanthamoeba keratitis: the quest for alternative antiprotozoal chemotherapy. Eye 1994;8:555-63.

14 Seal DV, Hay J. Contact lens disinfection and Acanthamoeba: problems and practicalities. Pharm f 1992; 248:717-9.

15 Seal DV, Hay J, Devonshire P, Kirkness CM. Acanthamoeba and contact lens disinfection: should chlorine be discontinued? Br f Ophthalmol 1993;77:128.

16 Sarwar N, Griffith GAP, Loudon K, Tullo AB, Efron E. Acanthamoeba keratitis associated with disposable hydrogel contact lenses disinfected daily with chlorine-based care system. F Br Contact Lens Assoc 1993;16:15-8.

17 Illingworth CD, Cook SD, Karabatsas CH, Easty DL. Acanthamoeba keratitis: risk factors and outcome. $\mathrm{Br} \mathscr{f}$ Ophthalmol 1995;79:1078-82.

18 Radford CF, Bacon AS, Dart JKG, Minassian DC. Risk factors for Acanthamoeba keratitis in contact lens users: a case-control study. BMF 1995;310:1567-70.

19 Seal DV, Hay J. Risk factors for Acanthamoeba keratitispopulation study is required to confirm results. BMF 1995; 311:808.

20 Hagan $M$, Newman M, Wright E, Dolin P, Johnson GJ. Causes of suppurative keratitis in Ghana. Br $\mathcal{F}$ Ophthalmol 1995;79:1024-8.

21 Martin MJ, Rahman MR, Johnson GJ, Srinivasan M, Clayton YM. Mycotic keratitis: susceptibility to antiseptic agents. Int Ophthalmol 1996;19:299-302.

22 Kaspar Mino de H, Zoulek G, Paredes ME, et al. Mycotic (microbiologic) keratitis in Paraguay. Mycoses 1991;34: 251-4.

23 Thomas PA. Mycotic keratitis: an under-estimated mycosis. 7 Med Vet Mycol 1994;32:252-6.

24 Williams G, Billson F, Husain R, et al. Microbiological diagnosis of suppurative keratitis in Bangladesh. Br $\mathcal{F}$ Ophthalmol 1987;71:315-21.

25 Dunlop AAS, Wright ED, Howlader SA, et al. Suppurative corneal ulceration in Bangladesh. A study of 142 cases examining the microbiological diagnosis, clinical and epidemiological features of bacterial and fungal keratitis. Aust NZ Ophthalmol 1994;22:105-10.

26 Ormerod LD. Causation and management of microbial keratitis in subtropical Africa. Ophthalmology 1987;94: $1662-8$

27 Sharma S, Srinivasan M, George C. Acanthamoeba keratitis in non-contact lens wearers. Arch Ophthalmol 1990;108: 676-8.

28 Pyott A, Hay J, Seal DV. Acanthamoeba keratitis: first recorded case from a Palestinian patient with trachoma. $\mathrm{Br}$ f Ophthalmol 1996;80:849.

29 Chander J. Prevalence of fungal corneal ulcers in northern India. Infection 1994;22:207-9.

30 Thomas PA. Keratomycosis. In: Hay RJ, ed. Tropical fungal infections: Baillière's clinical tropical medicine and communicainfections: Bailliere's clinical tropical medicine and communica-
ble diseases. London: Baillière Tindall, 1989; vol 4 (1):26986.

31 Wahl JC, Katz HR, Abrams DA. Infectious keratitis in Baltimore. Ann Ophthalmol 1991;23:234-7.

32 Liesegang TJ, Forster RK. Spectrum of microbial keratitis in South Florida. Am f Ophthalmol 1980;90:38-47.

33 Schein OD, Wasson PJ, Boruchoff SA, Kenyon KR. Microbial keratitis associated with contaminated ocular medications. Am F Ophthalmol 1988;105: 361-5.

34 Wilhelmus KR, Gee L, Hauck WW, et al. Herpetic Eye Disease Study. A controlled trial of topical corticosteroids for herpes simplex stromal keratitis. Ophthalmology 1994;101: 1883-96.

35 Heathcote JG, McCartney ACE, Rice NSC, Peacock J, Seal DV. Endophthalmitis caused by exogenous nocardial infec-
tion in a patient with Sjogren's syndrome. Can $\mathcal{f}$ Ophthalmol 1990;25:29-32. 
36 Hyndiuk RA, Eiferman RA, Caldwell DR. Comparison of ciprofloxacin ophthalmic solution $0.3 \%$ to fortified
tobramycin-cefazolin in treating bacterial corneal ulcers. tobramycin-cefazolin in treating
Ophthalmology 1996;103:1854-63.

37 O'Brien TP, Maguire MG, Fink NE, et al. Efficacy of ofloxacin vs cefazolin and tobramycin in the therapy for bacterial keratitis. Arch Ophthalmol 1995;113:1257-65.

38 Stein RM, Clinch TE, Cohen EJ, et al. Infected vs sterile corneal infiltrates in contact lens wearers. Am $\mathcal{F}$ Ophthalmol 1988;105:632-6.

39 Bates AK, Morris RJ, Stapleton F, Minassian DC, Dart JKG. 'Sterile' corneal infiltrates in contact lens wearers. Eye 1989;3:803-10

40 Binder PS, Rasmussen DM, Gordon A. Keratoconjunctivitis and soft contact lens solutions. Arch Ophthalmol 1981;99:87-90.

41 Holden BA, Hood DL, Grant T, et al. CLARE (contact lens associated acute red eye) due to Gram negative bacteria. associated acute red eye) due to Gram negative bacteria.
$C L A O \mathcal{1}$ 1996;22:47-52.

42 Kenyon KR, John T. Complications of soft contact lenses. In: Ruben M, Guillon M, eds. Contact lens practice. London: In: Ruben $M$, Guillon M, eds. Contact lens
Chapman \& Hall 1994, Chapter 46;1070.

43 Mondino BJ, Groden LR. Conjunctival hyperaemia and corneal infiltrates with chemically disinfected soft contact lenses. Arch Ophthalmol 1980;98:1767-70.

44 Stapleton F, Dart J, Minassian D. Non-ulcerative complications of contact lens wear. Relative risks for different lens types. Arch Ophthalmol 1992;110:1601-6.

45 Pimenides D, Steele CF, McGhee CNJ, Bryce IG. Deep corneal stromal opacities associated with long term contact lens wear. Br f Ophthalmol 1996;80:21-4.
46 Suchecki J, Ehlers WH, Donshik PC. Peripheral corneal infiltrates associated with corneal lens wear. CLAO F 1996; 22:41-6.

47 Goodall K, Brahma A, Ridgway A. Acanthamoeba keratitis masquerading as adenoviral keratitis. Eye 1996;10:643-4.

48 Raizman M. Corticosteroid therapy of eye disease. Arch Ophthalmol 1996;114:1000-1.

49 Aronson SB, Moore TE. Corticosteroid therapy in central stromal keratitis. Am $\mathcal{F}$ Ophthalmol 1969;67:873-96.

50 Stern GA, Buttross M. Use of corticosteroids in combination with antimicrobial drugs in the treatment of infectious corneal disease. Ophthalmology 1991;98:847-53.

51 Groden LR, Brinser JH. Outpatient treatment of microbial corneal ulcers. Arch Ophthalmol 1986;104:84-6.

52 Cruz OA, Sabir SM, Capo H, Alfonso EC. Microbial keratitis in childhood. Ophthalmology 1993;100:192-86.

53 Clinch TE, Palmon FE, Robinson MJ, et al. Microbial keratitis in children. Am f Ophthalmol 1994;117:65-71.

54 Perry LD, Brinser JH, Kolodner H. Anaerobic corneal ulcers. Ophthalmology 1982;89:636-42.

55 Artistimuno B, Nirankari VS, Hemady RK, Rodrigues MM. Spontaneous ulcerative keratitis in immunocompromised patients. Am f Ophthalmol 1993;115:202-8.

56 Hemady RK. Microbial keratitis in patients infected with the human immunodeficiency virus. Ophthalmology 1995; 102:1026-30.

57 Lee P, Green R. Corneal biopsy—indications, techniques and a report of a series of 87 cases. Ophthalmology 1990;97: 718-21. 